\title{
REVISTAMARACANAN
}

Dossiê

\section{Narrativas orais como fontes para uma compreensão histórica da experiência vivida}

\section{Oral narratives as sources for a historical understanding of the lived experience}

\author{
Robério Américo do Carmo Souza \\ Universidade da Integração Internacional da Lusofonia Afro-brasileira \\ americosouza@unilab.edu.br
}

\begin{abstract}
Resumo: O presente artigo toma como objeto aquilo que chamamos de narrativa oral, como objetivo de refletir sobre como o relato oral pode ser construído como fonte para uma compreensão histórica das experiências vividas pelo narrador em seu passado, a partir do modo como ele as atualiza no momento da enunciação. Realizou-se um esforço para pensar as formas e caminhos de construção de uma identidade narrativa por quem nos conta suas histórias e de como esse fazer-se produz sentido para o vivido numa trama marcadamente simbólica, eivada de sentimentos e desejos para si e para o outro, aquele para quem se narra.
\end{abstract}

Palavras-chave: Narrativa oral; Memória; Oralidade; História.

\begin{abstract}
The present paper takes as object of investigation what we call oral narrative having as objective to reflect on how oral narrative can be constructed as a source for a historical understanding of the experiences lived by the narrator in his past frim the way he updates them at the moment of enunciation. $\mathrm{Na}$ effort was made to analyze the ways of construction of a narrative identity used by whom tells us their Stories and how this making-oneself produces meaning for the lived experiences in a markedly symbolic plot full of feelings and desires for oneself and for the other the to whom one's life is narrated.
\end{abstract}

Key words: Oral narrative; Memory; Orality; History.

Recebido: Abril de 2017

Aprovado: Junho de 2017 
Era uma vez, o homem e seu tempo. ${ }^{1}$

O narrador é a forma na qual o Justo se encontra a si próprio. ${ }^{2}$

\section{Entre a vivência e o ofício}

Quando eu era criança, minha mãe me colocava para dormir contanto histórias de sua infância no campo. Era um ritual que eu aguardava ansioso durante todo o dia e que se repetia a cada noite. Foi assim durante anos, até que a adolescência chegou e outros interesses passaram a tomar minha atenção.

Ainda pequeno, descobri que nem todas as histórias que me embalavam os sonhos com romance e aventura haviam se passado exatamente como ela contara. Mesmo que inventadas, elas cumpriram o importante papel de me conectar com o passado de minha mãe, de construir entre nós um forte elo de mútua compreensão e intimidade. Para mim seus relatos não eram "falsos", eles recriavam a verdade de forma transversal e mais intensa, por isso mesmo, mais atraente e empolgante. O que me cativava e me mantinha atento aos seus relatos não era a veracidade de sua narrativa, mas o jogo entre realidade e fantasia que era a própria substância das tramas com que ela me entretinha. Nunca, nem mesmo depois de adulto, levei até ela questionamentos sobre a veracidade do que me contara. Havia entre nós um pacto velado, entre narrador e ouvinte, pelo qual acreditávamos piamente na verdade da "ficção" de suas memórias.

Foram as histórias de minha mãe que, antes dos contos infantis e da literatura mais densa, descoberta na juventude, me deram a primeira experiência de "leitor", que me conduziram ao necessário aprendizado para ler o mundo como uma construção e não como uma verdade absoluta e imutável. Isso fez de mim um leitor aficionado por relatos de vida, onde a invenção e a realidade dialogam numa dinâmica promíscua e bela, que torna possível a construção de significado para as experiências vividas.

Esta experiência familiar por certo contribuiu para minha escolha de carreira profissional e, de modo mais direto, influiu na escolha da trama entre memória, oralidade e narrativa como esteio de minhas reflexões no campo teórico-metodológico do saber-fazer historiográfico. Esta trajetória tem fundamental importância na e para a problematização que inspira e possibilita a discussão proposta neste artigo.

\footnotetext{
${ }^{1}$ Título do quinto LP do compositor e cantor Belchior, lançado em 1979.

2 BENJAMIM, Walter. Sobre Arte, Técnica, Linguagem e Política. Lisboa: Relógio D’Água, 1992, p. 57.
} 


\section{O problema}

Como o título já prenuncia, este artigo tem como objeto aquilo que chamamos de narrativa oral, ou seja, as reflexões aqui propostas foram construídas a partir de uma pergunta básica: como o narrador recorda e constrói seu relato oral das experiências que viveu em seu passado, atualizando-as no momento da enunciação?

Por isso mesmo, não se versa aqui sobre as marcas da oralidade no discurso narrativo, nem sobre o processo de sua transposição para o escrito, temas que abordei em artigo publicado anteriormente. ${ }^{3} \mathrm{O}$ objetivo é pensar as formas e caminhos de construção de uma identidade narrativa por quem nos conta suas histórias e de como esse fazer-se produz sentido para o vivido numa trama marcadamente simbólica, eivada de sentimentos e desejos para si e para o outro, aquele para quem se narra.

\section{A representação do ausente}

As narrativas orais, nos ensina Alessandro Portelli, são ditadas pela memória e, por isso mesmo, se tornam elas mesmas uma ação contra o esquecimento (que é também parte de como a memória opera) e, não raro, respondem por um certo temor de exílio. É legítimo afirmar, então, que a narração é a concepção mediadora entre o tempo vivido e a memória que dele se (des)construiu. O narrador atualiza e dá forma a seu passado no processo mesmo de narrar que, como uma "lançadeira no tear", se move livremente no tempo, para frente e para trás, mas - em sua condição de narrativa - sem a possibilidade de interromper a trama, mas sendo capaz de dar a ela forma e textura únicas. ${ }^{4}$

As narrativas orais permitem adentrar um fascinante campo de reflexões para a História, em especial para quem compreende o importante papel que ela desempenha na democratização do conhecimento. Ao mesmo tempo em que nos dá acesso a experiências que de outra forma não alcançaríamos, elas desvelam o processo próprio da narrativa, dando a possibilidade de formular problemáticas importantes para a compreensão do homem e sua relação com o tempo.

O que escolhem os narradores para contar sobre suas vidas? Que características circunscrevem a narrativa oral do vivido? O que aproxima e o que distancia a narrativa oral de uma escritura autobiográfica e de um relato testemunhal (produzido em inquéritos policiais e processos judiciários)? O que é narrar o vivido?

${ }^{3}$ SOUZA, Robério Américo. Interpretação de gestos e sentimentos: a teatralidade nas narrativas da história oral. Revista História Agora, v. 9, n. 9, jun./ago. de 2010. (Dossiê: História Oral)

${ }^{4}$ PORTELLI, Alessandro. El tempo de mi vida: la funciones del tiempo en la historia oral. In: LOZANO, Jorge A. (org.). História Oral. Cidade do México: Instituto Mora, 1997. 
Em primeiro lugar poderíamos afirmar que narrar experiências vividas (direta ou indiretamente) é reproduzir, por meio da linguagem, algo que passou, que já não existe, é tornar presente o ausente. Narrar é, portanto, representar o passado sob a percepção do narrador, ou seja, é reconstruir "o que se passou" graças à atualização que dele se faz no presente, na trama das recordações que se formam no momento mesmo da enunciação do relato. Falar em representação implica compreender que o que se faz é uma reconstrução do passado - objeto ausente - por meio da costura realizada pelos mecanismos da memória: lembrança e esquecimento. É por meio da trama tecida pela memória, que o sujeito se relaciona com o tempo passado e o atualiza no presente da narrativa que enuncia.

Em síntese, é possível afirmar que o relato oral permite relacionar o passado com o presente de que participa o narrador, assim como pode criar - e de fato cria - uma expectativa de futuro. O relato guarda em si o potencial de articular, de modo dinâmico e efêmero, mas também intenso e rico, toda a temporalidade do sujeito que relata. É isso o que propõe Paul Ricoeur, quando afirma que o relato é o meio privilegiado que a linguagem nos oferece para que possamos dar conta daquilo que, de outra forma, não seria possível, posto que se encontra no tempo imediato, carecendo da consciência reflexiva que só o distanciamento temporal pode dar. ${ }^{5}$

A experiência temporal é uma importante dimensão da existência humana, que por vezes nos custa compreender com clareza. Narrar o vivido permite ao ser humano dar sentido ao seu lugar no mundo, construir sua historicidade, tornar-se sujeito da história.

Espontâneas, ou estimuladas por um interlocutor, as narrativas orais carregam consigo a imperiosa necessidade do ser humano de oferecer uma resposta à clássica pergunta: quem sou? Definir quem sou, afirma Flannery O'connor, somente se torna possível na experiência narrativa, pois nos tornamos sujeitos na medida do que podemos narrar, do que podemos significar. ${ }^{6}$

Como a autobiografia, a narrativa oral se realiza como uma leitura, uma interpretação da experiência vivida ${ }^{7}$, por quem a viveu. No entanto elas se diferenciam em algo fundamental, o suporte pelo qual ganham vida. A autobiografia se apresenta como texto escrito, é fruto da racionalidade letrada de seu protagonista, que se organiza em estrutura de caráter eminentemente disciplinado, formal e homogêneo. A narrativa oral, por sua vez, se faz dentro de um espectro de maior liberdade de enunciação, polissemia e dinamismo mais intenso. Para além de serem aspectos de forma, estas distinções são elementos balizadores das escolhas do que se narra e dos sentidos possíveis de atribuir às experiências passadas e presentes.

5 RICOEUR, Paul. ¿És la história de vida un espacio al margen del poder? In: LOZANO, Jorge A. (org.). História Oral. Cidade do México: Instituto Mora, 1997.

${ }^{6}$ O'CONNOR, Flannery. La nature et le but de la narration. Paris: Éditions Gallimard, 1978, p. 47-48.

7 Experiência vivida tem aqui o sentido que Ihe deu E.P. Thompson, em seu livro A Miséria da teoria, ou um planetário de erros, publicado originalmente em 1979. Para o historiador britânico, os sujeitos historicamente constituídos vivem a vida como uma experiência dialógica entre as estruturas e as subjetividades, que, a um só tempo, nega, opõe e resiste, estabelece mediações, é espaço de prática, intervenção, recusa, processo de formação de identidades de classe, poderíamos acrescentar, de gênero, de geração e etnias. 


\section{A metáfora do passado}

Considerando que o relato de memória se define como uma representação pessoal, particular, do tempo passado, feita pelo narrador na busca de elaborar sentidos e significados para sua experiência de vida, será suficiente a simples conjugação do verbo na primeira pessoa do passado para distinguir o relato de memória da narrativa de ficção?

Segundo Ricoeur, a reconstrução do passado está presente em toda narrativa, na medida em que reconstruir implica tanto na seleção de acontecimentos, como na elaboração de uma unidade significativa. ${ }^{8}$ Como, então, diferenciar a narrativa oral de memória da narrativa ficcional, se nas duas temos como elemento central a representação de um objeto ausente?

Para isso é preciso, primeiramente, frisar que a noção de representação do mundo implica na existência de um vínculo de conhecimento entre sujeito e objeto de referência. Seria correto, então, afirmar que o que caracteriza a ficção é a ausência de referência, ou seja, na ficção o sujeito se refere a um objeto que não existe na realidade? Responder afirmativamente a esta pergunta implica aceitar o princípio segundo o qual não existe referência se não existe o objeto ao qual a narrativa se refere. Este princípio estabelece uma relação entre uma problemática semântica (referência da linguagem) e outra epistemológica (a verdade do que existe). Tomando essa ideia como correta, deve-se afirmar que falar do real sob o princípio da correspondência é dizer a verdade, desta forma, a noção de representação torna-se dependente da referência. Dentro dessa linha de raciocínio, o discurso ficcional, que não se propõe a proferir certezas, se diferencia em absoluto da narrativa oral que, assim como o discurso científico, se propõe a dizer a verdade. Pensar assim é desconsiderar que a fluidez e a pluralidade próprias da linguagem são os elementos que animam de possibilidades a narrativa.

Vejamos: se a narrativa oral, como toda narrativa humana, representa o objeto ausente no caso a experiência pretérita - qual é a sua referência, posto que o objeto a que se refere não mais existe e trazê-lo ao presente implica em realizar uma operação de reconstrução?

Em oposição à concepção rankeana da história, que toma a percepção do passado como registro do que realmente aconteceu, Paul Ricoeur propõe a compreensão de que o passado que acessamos a partir do presente é uma construção discursiva. Em outras palavras, o que temos é o descolamento conceitual da noção de referência, que, na impossibilidade do contato com o objeto em si, toma como referente a representação que dele se constrói. ${ }^{9}$

Deste modo, se nos estudos históricos o objeto de referência inexiste e trazê-lo de volta implica necessariamente em reconstruí-lo, é correto afirmar que a escrita da história é uma ficção, como propôs Hayden White? Não. Mesmo diante da impossibilidade de lidar diretamente com seu

\footnotetext{
${ }^{8}$ RICOEUR, Paul. Tempo e narrativa. Tomo II. Campinas: Papirus, 1995, p. 72.

${ }^{9}$ Idem.
} 
objeto de estudo, que a ele chega pela mediação das fontes, por meio de olhares de outros sobre os acontecimentos passados (inclusive textos ficcionais), o historiador conduz sua produção de conhecimento na perspectiva de uma compreensão teórica e metodologicamente orientada da experiência humana no tempo.

Transportando esta linha de raciocínio para análise da narrativa oral, na qual o objeto de referência igualmente não mais existe, temos uma situação semelhante, mas com uma diferença crucial, aqui não há interdição à elaboração ficcional como forma de enunciar uma referência indireta do passado, mediada pela ação simbólica que a memória opera. Isso significa que a referência não corresponde a uma correlação substancialista, ${ }^{10}$ na qual o signo designa o objeto, mas se realiza como metáfora. O relato de memória deve ser tomado como uma construção de linguagem simbólica.

O historiador, como bem observou Michel de Certeau, não tem contato com o passado, mas sim com as sobras dele, que a ele chegaram; ${ }^{11}$ assim também é com o narrador, que não possui mais que os restos de suas experiências passadas, tal como sua memória as reteve.

A narrativa oral não reproduz o passado, nem "encontra" seu sentido, mas produz ela mesma o passado e seus sentidos, por vezes lançando mão de fortes doses de imaginação e criatividade.

Tal como faz o historiador em seu ofício, o narrador não somente relata o passado "tal como ele foi", mas, constrói dele uma interpretação, a qual organiza sob a influência dos valores, das crenças e das ideais que o orientam no tempo presente. Todavia, diferente do historiador, que lida com algo estranho a ele e cujo trabalho pressupõe observação metodológica e comprovação (fontes) do que é observado, produzindo, assim, uma interpretação dedutiva, o narrador lida com matéria da qual é íntimo, cujo estranhamento é impossível, e produz seu relato sob a égide de sentimentalidades e simbolismos, elaborando uma "reescrita" mais próxima da metáfora que da dedução.

A diferença entre a narrativa ficcional e a narrativa oral reside, entre outros, no entendimento de que a primeira se realiza - e isso é condição elementar de sua existência - sem pretensão alguma de dizer a verdade sobre a realidade, enquanto que a segunda constrói sua representação da realidade com um forte sentido de enunciar a verdade. A ficção não tem como meta produzir certezas, mas superar os limites que o mundo real nos impõe. Isto implica, como afirma Wofgang Iser, em uma estrutura de duplo significado: "sempre há um significado

10 O termo "substancialista" é utilizado, neste texto, para conceituar aquilo que é constituído de uma substância essencial, ou definido a partir da crença em essências humanas imutáveis, sobre as quais as transformações históricas não atuam.

${ }^{11}$ CERTEAU, Michel de. A escrita da História. 2a ed. Rio de Janeiro: Editora Forense Universitária, 2000. 
manifesto que bloqueia outro latente, que, por sua vez, retira a sua relevância do que é manifesto". ${ }^{12}$

A narrativa ficcional se faz por meio de um jogo de ocultação e revelação. Ela dá a entender que o que diz deve ser lido como se fizesse referência a algo concreto e preciso, quando, em verdade, todas as referências estão ocultas e precisam ser imaginadas. A ficção pressupõe uma separação clara entre dois mundos, aquele que é real e aquele que é fruto da imaginação consciente do seu criador.

A narrativa oral se pretende enunciadora da realidade vivida pelo narrador em sua "plena concretude", no entanto, compartilha com a narrativa ficcional a possibilidade de romper os limites dessa mesma concretude, num movimento quase sempre direcionado para reinvenção do sujeito. Isso se realiza não apenas pela ocultação sob uma multiplicidade de disfarces, que operam como modos de "auto-representação", mas também - e, sobretudo - fundindo o princípio com o fim, realizando uma impossibilidade concreta, que é unir passado e presente.

A narrativa oral por vezes encena realidades improváveis, mesmo inacessíveis dentro experiência vivida, no esforço de construir significados para a trajetória de vida do narrador. Isso ocorre, por exemplo, quando o narrador relata uma experiência vivida em que ele atua sob a condição e orientação de valores e crenças que possui hoje e que não teria como possuir no tempo em que aquilo que narra ocorreu.

Por outro lado, o narrador percorre as veredas da memória na busca por comprovar a realidade do que conta, muitas vezes lançando mão de "relatos de relatos". Ou seja, por vezes constrói sua narrativa não apenas com as lembranças do que protagonizou, mas também com as recordações do que apreendeu nas narrativas que ouviu de outros. Ele faz isso para completar vazios que o esquecimento, que assim como a lembrança é um componente da memória, provocou, mas, também, para trazer para si a experiência e o discurso da comunidade com a qual constituiu um vínculo de pertencimento.

É na tensão entre o individual e o coletivo que a narrativa oral avança na busca de se fazer legítima, de ser uma história digna de se contar, ou seja, de ser uma história que pode ser compreendida e reconhecida pelo outro.

\section{O narrador: leitor e escritor de si mesmo}

A memória atua como a mediadora entre o tempo vivido e a narrativa, vinculando-se à consciência subjetiva na (re)construção de uma lembrança individual. Apenas a memória pode dar conta das diferentes temporalidades que perpassam o sujeito e o faz por meio da narrativa oral,

12 ISER, Wolfgang. O fictício e o imaginário: perspectivas de uma antropologia literária. Rio de Janeiro: Ed. UERJ, 1996, p. 38. 
do relato de memória. Por meio do relato sobre a infância e a juventude, o narrador adulto constrói uma ordenação inteligível- por vezes inteligível apenas para si mesmo - para as experiências vividas, ou para o que delas lhe restou. Neste processo de objetivação dos fragmentos que restaram dessas experiências, o narrador vai construindo, graças à atualização que a memória Ihe proporciona, a sua existência narrativa, uma identidade que considera justa para si. Deste modo, a identidade, estruturada e vocalizada como narrativa, assume a configuração de um "projeto", que, nos ensina Gilberto Velho, se "constitui uma conduta organizada para atingir finalidades específicas", ou seja, imprime um sentido à vida do narrador, dando-Ihe direção e significado. ${ }^{13}$

No movimento de construção de identidade, a memória individual articula-se com a memória coletiva, como a define Maurice Halbwachs. Essas lembranças compartilhadas são elemento basilar no desenvolvimento de pertencimento social, de identificação com o grupo em que se está inserido. ${ }^{14} \mathrm{Na}$ construção narrativa, o pertencimento social e a identificação de grupo são componentes que se somam às experiências vividas, preenchendo lacunas por elas deixadas e contribuindo direta e decisivamente para atribuir-Ihes sentido, na complexa trama de construção da identidade individual.

Essa identidade se desdobra no tempo e nos permite significar a nós mesmos e compreender o mundo em que vivemos, possibilitando passar de uma temporalidade individual, que é a da biografia, a uma temporalidade coletiva, que é a da história. A narrativa oral, neste sentido, se traduz em luta contra o esquecimento. Em outras palavras, o narrador conta a sua história para que possa permanecer na história, para que seja lembrado.

Os relatos de que o narrador é protagonista não são um material objetivo e estático, nem uma explicação dos fatos, mas um modo de narrar a vida segundo um enfoque específico. Este enfoque, ou perspectiva, corresponde ao recorte que o narrador faz da realidade que acomoda em seu relato: configuração por meio da qual constitui sua identidade narrativa. Esse recorte, como o próprio nome sugere, implica em determinada seleção de episódios vividos - escolha de uns, rejeição de outros -, que corresponde à decisão do narrador de como melhor lhe convém, no momento específico em que narra, ordená-los e enunciá-los.

Nenhum acontecimento é em si mesmo cômico, trágico, ou fantástico, estes sentidos lhe são imputados a partir de conceituações que balizam a cultura de que se é tributário. Essas conceituações são paradigmas estruturantes fundamentais para a forma como percebemos e registramos nosso passado.

Nada é retido na memória como imutavelmente trágico ou cômico, mas é concebido, dessa ou daquela forma, a partir da perspectiva que configura a construção da narrativa que sobre elas se constrói, no momento presente em que ela se constrói. Dito de outro modo, o que hoje é

\footnotetext{
${ }^{13}$ VELHO, G. Memória, identidade e projeto. In: Projeto e metamorfose: antropologia das sociedades complexas. Rio de Janeiro: Zahar, 1994, p. 97-113

${ }^{14}$ HALBWACHS, Maurice. Memória Coletiva. São Paulo: Editora Revista dos Tribunais, 1990, p. 48.
} 
narrado como trágico, amanhã poderá ser relatado como cômico, a depender de como o presente do narrador se colocará em diálogo com seu passado.

Para dar sentido ao que narra, o narrador escolhe a forma, a estrutura narrativa, sob a qual aquilo que relata deve aparecer. Faz isso com base nos moldes e esquemas narrativos que conhece e com os quais compreende que melhor irá comunicar o que pretende, como melhor irá construir uma identidade de si, para si e para o outro.

Os narradores moldam as experiências que relatam com base em estruturas narrativas que podem ser comparadas à lenda, ao épico, ao realismo fantástico, à novela sentimental, à comédia, etc. Ou seja, a narrativa oral é construída com o recurso às operações características do universo de elaboração da narrativa ficcional, posto que estas são as formas narrativas que a cultura que conhecemos nos legou.

Segundo Ricoeur, as formas narrativas são um tipo de suporte para o que ele chama de "sedimentação narrativa", que é constituída pelo conjunto de relatos de uma determinada cultura. A inspiração da narrativa se faz dentro do espaço cultural simbólico em que o narrador está circunscrito, assim, estabelece limites ou horizontes possíveis, que permitem à linguagem captar e elaborar a experiência temporal. Este conceito é operacionalizado em diálogo com outro que Ihe complementa: o conceito de "inovação", que se define como a capacidade que o narrador possui de criar o novo a partir da sua subjetividade. É pelo movimento dialético entre a sedimentação e a inovação que se constitui a tradição e que podemos explicar os tipos de tramas narrativas e seus processos de transformação. ${ }^{15}$

Essa tradição pode ser definida como o conjunto de relatos que resultam das ações de produção e consumo de narrativas, quer orais, quer escritas. Esta circularidade permite a sedimentação dos relatos, bem como possibilita que uma comunidade construa sua identidade coletiva. Movimento semelhante se dá com o indivíduo que conta, por meio da narrativa oral, aquilo que experenciou em seu passado, tornando-se a um só tempo leitor e escritor destas mesmas experiências.

Também operam de modo circular as chamadas atividades miméticas: prefiguração, configuração e refiguração. A refiguração ocorre ao se estabelecer um vínculo com a relação mimética de prefiguração mediada pela configuração da narração em si. É desse modo que o leitor - sujeito real - se apropria dos significados que o vinculam com o herói - sujeito fictício - de uma ação, por meio da leitura do texto. O leitor é refigurado por um processo por meio do qual ele se figura como tal. Ou seja, ele se identifica com um outro, que mesmo sendo fictício, se torna real como escopo da identificação experimentada.

A partir desta compreensão, é possível vincular as formas tradicionais de estruturar histórias com a ideia de identidade que se constitui por meio da narrativa oral. A identidade narrativa seria, então, a identidade que o ser humano - necessariamente percebido como sujeito

${ }^{15}$ RICOEUR, Paul. Tempo e narrativa... Op. cit., p. 72. 
reflexivo-dialógico - constrói, por meio da operação narrativa de suas lembranças do passado. Isto implica romper com a noção de um sujeito substancialista e afirmar a ideia de sujeito atravessado por outros, mediado por símbolos, linguagens e narrativas, constituído pelo tempo e pelas transformações que nele se processam na dialética histórica entre sujeito e objeto.

A enunciação de uma narrativa oral se faz na perspectiva da organização das experiências vividas pelo narrador. Organização que Ihe permite construir uma unidade identitária reconhecível pelo outro, mas que nem sempre tem o resultado esperado. Em grande medida a construção da identidade se faz em função da busca de reconhecimento, bem como apenas se torna possível de existir por meio deste reconhecimento. O olhar alheio, do outro, daquele que é exterior, do mundo, enfim, nos enxerga por meio da unidade significativa que construímos. E nós a construímos porque por este olhar somos e precisamos ser percebidos.

No processo de formação do EU, o narrador toma para si um conjunto de normas e valores que ele compreende como capazes de tornar aquilo que narra inteligível ao OUTRO. O processo de formação da identidade narrativa se configura também em função daquilo que o narrador entende como expectativa, ou como necessidade de quem ouve.

Ao fazer um relato de memória o que buscamos é satisfazer o desejo de sermos identificados, de tornar inteligível, à experiência caótica que é viver. Ao fazer isso, nos tornamos narrador, mas também nos fazemos narração, texto. A narração se realiza como espaço simbólico, intersubjetivo, no qual se ordena o caos das experiências vividas, atribuindo-Ihes um sentido, construindo uma identidade, ainda que não definitiva, nem estática, mas, outrossim, fluída e mutável em sua relação com diferentes tempos e diversos outros.

A narrativa se converte em identidade, ou em esforço identitário, ao menos, por meio da invenção de uma figuração de vida do próprio narrador, dando um sentido às múltiplas vivências experimentadas; sentido que elas em si mesmas não possuem. Deste modo a vida se converte em texto, traduzindo a relação simbólica entre a experiência individual e o mundo. Tradução que somente é possível no discurso: apenas narrando, o sujeito é; apenas na narrativa ele constrói uma identidade ordenada e inteligível de si para o outro. A narrativa de memória tem o incrível poder de parar o tempo por um instante, de estabelecer um definido, mas não eterno, sentido para o passado vivido.

Assim como a narrativa oral se realiza como uma autoconstrução, o narrador não deve ser visto pelo historiador apenas como aquele que narra sobre si, mas como alguém que se constitui e se define como sujeito de sua própria história na narração e pela narração, pelo que esta deve ser tomada, também, como um gesto político.

A identidade narrativa se completa e se realiza como refiguração a cada narração. O EU é constantemente relido e resignificado, produzido e reproduzido, em cada novo relato das experiências vividas. 
Algumas narrativas expressam grande força argumentativa, erigida por meio de rigorosa unidade de sentido e ordenação precisa daquilo que se relata. Outras, por sua vez, compartilham com as narrativas ficcionais um maior grau de imprecisão, ensejando multiplicidades de sentidos e interpretações. Ambas, contudo, devem ser tomadas pelo historiador como a escritura que o narrador faz de si e do mundo, leitura que lhe é possível naquele momento, e que não pode ser tomada como a realidade em si mesma.

Todo relato de memória é em si um ensaio de metáforas. Isso, todavia, não pode ser confundido com irrealidade, ou ausência de concretude, mas como evidência de que a realidade, passada e presente, é sempre uma construção de seus sujeitos. Por isso a história oral, como adverte Verena Alberti, não deve ser idealizada como método de produção de documentos "verdadeiros", mas como recurso metodológico para produção e registro de narrativas constituídas pelas possibilidades de diálogo entre o eu narrador e o outro entrevistador. ${ }^{16}$

\section{Conclusão, ainda que não definitiva}

Como o narrador recorda e constrói seu relato das experiências que viveu em seu passado, atualizando-as no momento da enunciação? O que escolhe o narrador para contar sobre sua vida? Que características circunscrevem a narrativa oral do vivido? O que aproxima e o que distancia a narrativa oral de uma escritura autobiográfica e de um relato testemunhal (produzido em inquéritos policiais e processos judiciários)? O que é narrar o vivido?

Essas são as perguntas que conformaram uma problematização que, a um só tempo, provocou e orientou esta análise em forma de artigo. As repostas apresentadas tentaram definir, em forma e conteúdo de hipótese, o desejo, ou a necessidade consubstancial do ser humano de dar às experiências vividas no passado, e que compõem a sua memória de si e do mundo, uma forma de narrativa, pela qual ele Ihes atribui um sentido e constrói vínculos com o mundo (passado e presente), configurando para si uma identidade.

Desta compreensão podemos concluir - por agora, ao menos - que a narrativa oral, como um relato de memória, permite ao narrador dar testemunho do que já não mais existe, de um outro tempo, de uma cultura diferente daquela do presente, bem como possibilita ao historiador, como profissional dedicado a elaborar compreensões sobre o tempo, ter acesso a este testemunho. É ainda possível afirmar que a narrativa se faz, em parte, como forma de emocionar, comover, promover reflexão e, acima de tudo, despertar no OUTRO o reconhecimento e a compreensão do EU, sujeito que enuncia e protagoniza a própria narrativa.

Narrar uma vida não significa repetir em palavras uma história pronta e acabada, mas compô-la, tal e qual o escritor e seu texto. Isto implica numa atividade criativa que por vezes, no

${ }^{16}$ ALBERTI, Verena. Ouvir contar, textos em história oral. Rio de Janeiro: FGV, 2004, p. 16. 
esforço de se fazer mais real e, acima de tudo, mais crível, lança mão de recursos das narrativas (orais e escritas) que configuram sua formação cultural. Recursos imaginativos que, não raro, levam o narrador a encontrar no formato ficcional a maneira eficiente de dar sentido à realidade vivida.

Para chegar a esta compreensão o historiador precisa, antes de tudo, saber "ouvir contar", perceber e valorizar a narrativa para além da informação que ela traz, ocupando-se, também, do exercício investigativo sobre o como essa informação foi narrada, sobre os sentimentos e gestos que compuseram sua enunciação.

Assim como as narrativas que toma por objeto, as reflexões aqui desenvolvidas são fluídas e frágeis, e, também, não carregam nenhuma pretensão de estabelecer verdades ou paradigmas precisos, busca tão somente compartilhar muitas inquietações e alguns poucos prenúncios de compreensão do universo complexo e arredio que é a narrativa oral. Qualquer pesquisador que lance mão da tríade memória, oralidade e narrativa em seus estudos irá se deparar como uma seara rica em possibilidades e recompensas, mas igualmente espinhosa, onde se digladiam várias e complexas tendências teórico-metodológicas, além de importantes embates sobre ética. Todavia, não há recompensa sem riscos, pelo menos não as boas recompensas, por isso é preciso seguir pensando, discutindo, pesquisando.

Robério Américo do Carmo Souza: Professor de Teoria e Metodologia da Pesquisa e do Ensino de História do Instituto de Humanidades e Letras da Universidade da Integração Internacional da Lusofonia Afro-brasileira (UNILAB), Doutor em História Social pela UFF, Mestre em História Social pela Pontifícia Universidade Católica (PUC-SP) e Graduado em História pela UFC. 